\title{
The Impact of Corporate Culture on the Performance of Industrial Enterprises
}

\author{
Petra Urbanovičová'* , Miloš Čambál2 , Zdenka Guyrák Babel'ová3 \\ 1 Institute of Industrial Engineering and Management, Faculty of Materials Science and Technology in Trnava Slovak University of Technology in \\ Bratislava, Jána Bottu 25, 91724 Trnava, Slovakia \\ ${ }^{2}$ Institute of Industrial Engineering and Management, Faculty of Materials Science and Technology in Trnava Slovak University of Technology in \\ Bratislava, Jána Bottu 25, 91724 Trnava, Slovakia \\ 3 Institute of Industrial Engineering and Management, Faculty of Materials Science and Technology in Trnava Slovak University of Technology in \\ Bratislava, Jána Bottu 25, 91724 Trnava, Slovakia
}

\begin{abstract}
The goal of every industrial enterprise is to make profits since it means survival in a tough competitive environment. This is also closely connected with achieving a certain level of performance that is carefully monitored through individual indicators. Financial performance indicators (e.g. relative indicators, absolute indicators, etc.) are particularly monitored. Non-financial performance indicators are also very important, however, only little attention is paid to them in enterprises. Some non-financial performance indicators can be expressed numerically, but in units other they can reflect factors which significantly contribute to the overall company performance and cannot be figured out in monetary terms. Corporate culture is an important factor affecting non-financial indicators. Therefore, research carried out in frame of dissertation thesis at the STU Faculty of Materials Science and Technology in Trnava in 2018, was focused on the impact of corporate culture on performance of large industrial enterprises in the Slovak Republic. The research was also part of the VEGA 1/0348/17 project implementation: "The Impact of the Coexistence of Different Generations of Employees on the Sustainable Performance of Organisations". There are presented statistically verified and appropriate evaluated research results in the article.
\end{abstract}

Keywords: corporate culture, performance, non-financial indicators, corporate culture factors.

\section{Introduction}

Over the past years, many enterprises addressed the issue of corporate culture and its impact on performance of enterprises. For instance, Armstrong Competence Consulting and Competence Research Institute, cooperated with such enterprises in developing a study focused on identifying the corporate culture factors that are most considerably interconnected with performance and business results in enterprises. The monitored factors as an instrument of corporate culture analysis were verified in more than 100 companies from eight European countries, including the Slovak Republic and the Czech Republic. The data had been gathered by those companies for seven years. They were based on the corporate culture characteristics described by more than 20,000 employees in survey. The regression analysis of the data confirmed the surprisingly strong links between the variables representing corporate culture characteristics and the real business results of these companies as well as responses to the satisfaction of either employees or customers [1]. As other researches regarding corporate culture and performance in the past, the following can be mentioned [2]:

$\checkmark$ Dennison (1984) carried out one of the first quantitative researches and used the data from 34 US companies, 
examining the characteristics of corporate culture and performance achieved for over five years; Denison used the returns on investment and sales data for performance measurement and found that corporate culture correlated with financial performance;

$\checkmark$ Kotter and Heskett (1992) conducted one of the most extensive studies focused on culture and performance, using the data from 207 enterprises colluded to over a five-year period and applying different cultural indicators and the long-term company performance data; authors wanted to examine a correlation between strong culture and long-term performance and found that enterprises with appropriate corporate culture were performing better in their market environment than those less able to adapt to their environment;

$\checkmark$ Marcoulides and Heck (1993) also analysed the relationship between corporate culture and performance, applying the data from 26 enterprises and designed a model in which corporate culture was measured using several latent variables (organisational structure, corporate values, climate, individual values), and performance was measured based on the capital, market and financial indicators; the results showed that all latent variables had some impact on the company performance.

\section{Corporate Culture Factors and Their Impact on Non-Financial Indicators of the Industrial Enterprises Performance}

To understand the issue addressed in the research, we factually and concisely defined and explained in detail the concepts of "corporate culture factors" and "non-financial indicators", as well as our attitude to them in the research.

\subsection{Corporate Culture Factors}

The term "factor" in terms of corporate culture is used by the authors in different manners. Some authors write about the factors influencing the emergence of corporate culture (Figure $1-A)$, while others talk about factors of the corporate culture itself (Figure 1 - B) (i.e. that corporate culture has its own factors).

For example, the author Šiguta (2004) states in his publication that the following factors are involved in the emergence of corporate culture [3]:

1. factors of the environment (technical, economic, technological);

2. basic factors (A: personality profile of managerial staff, $B$ : rituals and symbols, (: communication);

3. management factors (A: company strategy, B: organisational structure of management, (: management systems).

Thus, Šiguta (2004) discusses the factors influencing the emergence of corporate culture (Figure $1-A$ ). However, we focused our research on the second group of factors, namely the corporate culture factors (Figure 1-B). For a better understanding of what is being dealt with in the contribution, we consider it important to precisely define and explain each word of the used terms, such as the "corporate culture factors". The term "factor" is defined as an element influencing something or actively involved in something [3].

The research dealt with the corporate culture factors influencing the company performance. The factors were divided into three main groups (Table 1) based on the study of literature and analysis of the knowledge acquired.

Group 1 of the corporate culture factors comprises the factors determined or, alternatively, specified/ assigned by an enterprise and directed inwards the company, i.e. its operations and employees. Group 2 comprises the factors also determined or, alternatively, specified/assigned by an enterprise, but directed towards its external environment, i.e. customers and suppliers. The final, Group 3 is composed of the corporate culture factors that are influenced by managers, namely by their behaviour and attitude to their subordinate employees. They result from the position of a manager and the attitude to their subordinates.

\subsection{Non-Financial Indicators of the Performance of Industrial Enterprises}

In the research, the term "non-financial indicators" mean the factors which can be numerically measured or quantified, but cannot be converted into monetary units. Table 2 lists the defined nonfinancial indicators that can be affected by individual corporate culture factors (corporate culture factors as defined above).

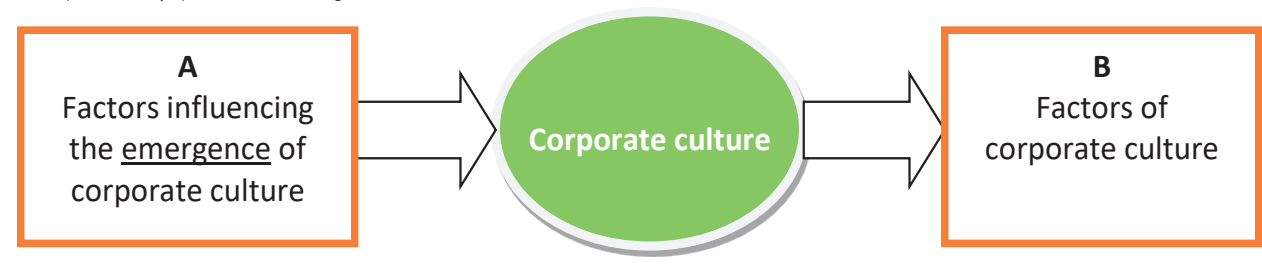

Fig. 1: Corporate Culture Factors (own design). 
Tab. 1: Corporate Culture Factors.

\begin{tabular}{|l|l|}
\hline $\begin{array}{l}\text { Corporate culture factors determined by an enterprise from the top level } \\
\text { inwards }\end{array}$ & $\checkmark$ employee motivation system \\
(Corporate Culture Factors Group 1) & $\checkmark$ company values \\
& $\checkmark$ company ideas and approaches \\
& $\checkmark$ company rules and principles \\
& $\checkmark$ troubleshooting process \\
& $\checkmark$ rituals and regular company events \\
& $\checkmark$ way of communication \\
\hline Corporate culture factors determined by an enterprise from the top level \\
outwards - for the external environment \\
(Corporate Culture Factors Group 2) & $\checkmark$ compaviour patterns in certain situations \\
\hline & $\checkmark$ company symbols (logos, image, design, signs) \\
\hline Corporate culture factors influenced by managers & $\checkmark$ product presentation/advertising \\
(Corporate Culture Factors Group 3) & $\checkmark$ complaints handling \\
& $\checkmark$ customer relationship \\
\hline & $\checkmark$ management style \\
& $\checkmark$ conflict resolution \\
\hline & $\checkmark$ atmosphere at the workplace \\
\hline & $\checkmark$ employee motivation \\
\hline & $\checkmark$ way of communication \\
& $\checkmark$ behaviour in crisis/stressful situations \\
\hline
\end{tabular}

Tab. 2: Non-Financial Performance Indicators.

\begin{tabular}{|l|}
\hline Non-Financial Performance Indicators \\
\hline$\checkmark$ turnover of employees/managers \\
$\checkmark$ speed of the employee selection process \\
$\checkmark$ absenteeism \\
$\checkmark$ sickness rate \\
$\checkmark$ ability to get talented employees \\
$\checkmark$ expertise of managers \\
$\checkmark$ quality of organisational processes \\
$\checkmark$ staff reputation among head-hunters \\
$\checkmark$ years of professional experience \\
$\checkmark$ proportion of new employees \\
$\checkmark$ employee satisfaction \\
$\checkmark$ proportion of employees coming up with new ideas \\
$\checkmark$ number of training days \\
$\checkmark$ percentage of jobs where skills were audited \\
$\checkmark$ percentage of people holding positions with agreed \\
development plans \\
$\checkmark$ stabilisation of employees/managers \\
\hline
\end{tabular}

\section{Research Methodology}

Large industrial enterprises operating in the Slovak Republic were the object of the research; the concept of large enterprise* is defined below. Large industrial enterprises were selected on the basis of the financial data database available on the website www.finstat.sk. In terms of their size, enterprises can be divided according several criteria, such as the number of employees, annual turnover, etc. We opted for the enterprise size classification by the number of employees (micro, small, medium-sized and large enterprises).

* Large enterprise is defined as an enterprise with more than 250 employees. Such an enterprise is independent business unit with a large number of employees, large turnover and capital strength, holding a significant position on the market that allows it to dictate terms to other market players. Large enterprises apply large-scale manufacturing programmes; typical features are stability of the manufacturing programme, high technical level of the manufacturing process and products, intense capital strength and enterprise orientation on national and international markets $[4,5]$.

The corporate culture factors affecting the performance of large industrial enterprises operating in the Slovak Republic including their monitoring and measurement, constituted the subject of the research. The quantitative research itself was carried out in the form of a questionnaire survey, which was distributed to all large industrial enterprises within the industries selected.

The number of the large industrial enterprises included in the research represents the size of the core set $N=364$. Based on the known size of the core set, we determined the size of the sample set using the following formula: 
$n=\frac{p \cdot(1-p)}{\frac{E^{2}}{z^{2}}+\frac{p \cdot(1-p)}{N}}=\frac{0.5 \cdot(1-0.5)}{\frac{0.05^{2}}{1.96^{2}}+\frac{0.5 \cdot(1-0.5)}{364}}=193.799=194$

where: $\mathrm{N}$ - core set; $\mathrm{n}$ - sample set; $\mathrm{p}$ - incidence of the examined symbol in the core set (in our case: $p=$ $0.5) ; E$ - maximum error of the estimate (in our case: $E=5 \%) ; z$ - quantile function of the standard normal distribution (based on the fact that we chose the estimate error of $5 \%$, implying that the confidence interval $(1-p)$ is then $95 \%$ ) (in our case: $z=1.96$ ).

The above-mentioned calculation enabled to determine the size of the sample set, i.e. the minimum number of enterprises, from which we needed to obtain completed questionnaires to make our research results relevant. Consequently, hypotheses were formulated. The hypothesis we validate is called a null (tested) hypothesis and abbreviated to $\mathrm{H}_{0}$, where no difference between the compared characteristics is assumed. If the tested hypothesis is not true, then the second option comes under consideration, which is an alternative hypothesis abbreviated to $\mathrm{H}_{1}[6]$.

\section{Hypothesis 1}

Ho: More than $40 \%$ of industrial enterprises operating in the Slovak Republic use non-financial indicators in addition to the financial indicators of company performance.

H1: Less than $40 \%$ of industrial enterprises operating in the Slovak Republic use non-financial indicators in addition to the financial indicators of company performance.

\section{Hypothesis 2}

$\mathrm{H}_{0}$ : There is no dependence between the optimised corporate culture and the achieved performance of industrial enterprises.

$\mathrm{H}_{1}$ : There is dependence between the optimised corporate culture and the achieved performance of industrial enterprises.

The data were collected in March - April 2018 using an electronic questionnaire. The data collection was aimed at obtaining the required number of completed questionnaires (in our case: at least 194). The selection of industrial enterprises was based on the above-mentioned classification of enterprises; we focused on large industrial enterprises with more than 250 employees. The enterprise industry was defined for a narrower range of enterprises. We managed to obtain 203 questionnaires completed by enterprises. Since the calculation showed the size of the sample set $n=194$, and it is mathematically true that $203>$ 194, the data obtained can be considered relevant and reliable.

For the formulated hypotheses, statistical methods were used to verify whether to accept or reject the formulated hypotheses. We took the following steps to test the hypotheses [6]:

\section{$\checkmark$ formulation of the null hypothesis $\mathrm{HO}$; \\ $\checkmark$ choice and calculation of test criteria; \\ $\checkmark$ choice of the level of significance; \\ $\checkmark$ interpretation of the result.}

Testing Hypothesis 1

When formulating the hypothesis, we assumed that the aspect under consideration (use of non-financial indicators) was observed in our sample set and it bore a feature of normal distribution.

It is true for $\mathrm{H}_{0}$ that $\pi<\pi_{0}$, where $\pi<0$. . If we reject the null hypothesis $\mathrm{H}_{0}$, then we accept the alternative hypothesis $\mathrm{H}_{1}$. It is true for rejection that $\mathrm{H} 0: \mathrm{Z}<-\mathrm{Z}_{1-\alpha}$.

\section{Choice and calculation of the test criteria:}

Verifying whether the sample set is large enough if:

\section{$n \pi \geq 5$}

$203 \cdot 0.4 \geq 5$

$81.2 \geq 5$ (TRUE) and if: $\quad n(1-\pi) \geq 5$

$203 \cdot(1-0.4) \geq 5$

$121.8 \geq 5$ (TRUE)
The above-mentioned calculation confirmed that the sample set is large enough for us to use the test statistics of the standard normal distribution $\mathrm{Z}$.

$$
Z=\frac{p-\pi_{0}}{\sqrt{\frac{\pi_{0}\left(1-\pi_{0}\right)}{n}}}=\frac{\frac{203}{364}-0.4}{\sqrt{\frac{0.4(1-0.4)}{364}}}=6.14
$$

where: $\mathrm{Z}$ - test criterion; $\mathrm{p}$ - sample proportion; $\pi$ average; $\pi_{0}$ - expected value $\left(\pi_{0}=0.4\right)$

\section{Choice of the level of significance:}

We chose the level of significance of $5 \%$, thus $\alpha=0.05$.

Interpretation of the result:

At the beginning, we argued that $\mathrm{H}_{0}: \mathrm{Z}<-\mathrm{Z}_{1-\alpha}$

$$
6.14<-1.65 \text { (UNTRUTH) }
$$

$\mathrm{Z}<-\mathrm{Z}_{1-\alpha}$, since in our case $\alpha=0.05$, then $\mathrm{Z}_{1-0.05}$ is $Z_{0.95}$, and we determined this value based on the standard normal distribution tables. Since the assertion that $6.14<-1.65$ is not true, we rejected it, i.e. we rejected the null hypothesis and accepted the alternative hypothesis $\mathrm{H}_{1}$, reading as follows "less than $40 \%$ of industrial enterprises operating in the Slovak Republic use non-financial indicators in addition to the financial indicators of 
company performance".

Testing Hypothesis 2

In order to test the Hypothesis 2, we used the "Test of Independence" to verify the dependence between two characters (A, B) occurring in one element (n). In our case, the element was a sample set of large industrial enterprises, and the individual characters were corporate culture and company performance. The A character represents "monitoring of nonfinancial performance indicators" and could appear in two variants ( $A_{1}-$ yes, $A_{2}-$ no). The $B$ character represents whether "the enterprise was operated with corporate culture for the past five years" and could appear in nine variants ( $\left.B_{1}-B 9\right)$. First, we entered the measured data from the questionnaire in the table of empirical probability (i.e. relative frequency) (Table 3).

Then, we calculated theoretical probability for each combination $\left(A_{i}, B_{j}\right) \frac{a_{i} b_{j}}{n}$ (Table 4).

The table below shows the differences between empirical and theoretical probabilities according to the equation $n_{i j-\frac{a_{i} b_{j}}{n}}$ (Table5).

We also verified independence and/or dependence of the characters using a test criterion according to the following equation:

$$
\chi^{2}=n \sum_{i=1}^{k} \sum_{j=1}^{m}\left(\frac{\left(n_{i j}-\frac{a_{i} b_{j}}{n}\right)^{2}}{a_{i} b_{j}}\right)
$$

Tab. 3: Empirical Probabilities.

\begin{tabular}{|l|l|l|l|l|l|l|l|l|l|l|}
\hline & B1 & B2 & B3 & B4 & B5 & B6 & B7 & B8 & B9 & Total \\
\hline A1 & 35 & 18 & 10 & 9 & - & - & - & - & - & 72 \\
\hline A2 & 4 & 2 & 2 & 1 & - & - & - & - & - & 9 \\
\hline Total & 39 & 20 & 12 & 10 & - & - & - & - & - & 81 \\
\hline
\end{tabular}

Tab. 4: Empirical Probabilities.

\begin{tabular}{|ll|l|l|l|l|l|l|l|l|l|}
\hline & B1 & B2 & B3 & B4 & B5 & B6 & B7 & B8 & B9 & Total \\
\hline A1 & 34.66666667 & 17.77777778 & 10.66666667 & 8.888888889 & - & - & - & - & - & 72 \\
\hline A2 & 4.333333333 & 2.222222222 & 1.333333333 & 1.1111111111 & - & - & - & - & - & 9 \\
\hline Total & 39 & 20 & 12 & 10 & - & - & - & - & - & 81 \\
\hline
\end{tabular}

Tab. 5: Difference between Empirical and Theoretical Probabilities.

\begin{tabular}{|l|l|l|l|l|}
\hline & B1 & B2 & B3 & B4 \\
\hline A1 & 0.333333333 & 0.222222222 & -0.666666667 & 0.111111111 \\
\hline A2 & -0.333333333 & -0.222222222 & 0.6666666667 & -0.1111111111 \\
\hline
\end{tabular}

Tab. 6: Calculation of Chi-squared Test Criterion.

\begin{tabular}{|l|l|l|l|l|l|}
\hline & B1 & B2 & B3 & B4 & Total \\
\hline A1 & 2.161918329 & 2.169032922 & 1.924382716 & 2.172016461 & 8.42735 \\
\hline A2 & 1.927825261 & 1.885596708 & 2.50617284 & 1.909465021 & 8.22906 \\
\hline Total & 4.08974359 & 4.05462963 & 4.430555556 & 4.081481481 & 16.65641 \\
\hline
\end{tabular}

We assume that the $A$ and $B$ characters are mutually independent, and our sample set $n$ is large-scale, thus the quantity $\chi^{2}$ will exhibit $\chi^{2}$ distribution with a number of degrees of freedom $k$. In our case, the number of degrees of freedom is $k=(r-1) \cdot(s-1)=(9-1) \cdot(2-1)=8$. We chose the level of significance of $5 \%$, and thus $\alpha=0.05$. The critical value $\chi_{\alpha}^{2}=15.5$ was determined from the statistical tables. If the relationship $\chi^{2}>\chi_{\alpha}^{2}$ is true, then we reject the null hypothesis, and the $A$ and $B$ characters under consideration can be considered dependent, otherwise the symbols are independent. $\chi^{2}>\chi_{\alpha}^{2}=>16.65641>15.5$ (THE RELATIONSHIP IS TRUE) 
As the above-mentioned relation is true, we also confirm the Hypothesis 2 and assert that "there is dependence between the optimised corporate culture and the achieved performance of industrial enterprises".

\section{Results}

A total of 203 large industrial enterprises were involved in the questionnaire survey, which, given the objectivity and relevance of the research, we consider sufficient (since the core set consisted of 364 enterprises and the sample set expected was at least 194 enterprises).

The most numerous group of enterprises involved in the research, almost 70\%, was composed of industrial enterprises with 250 - 999 employees, which we, however, assumed, as those companies also formed the most numerous group from our core set (301 enterprises). As much as a quarter of the enterprises involved in the research belonged to the automotive industry (25.12\%). Three-quarters of the enterprises involved in the research were subsidiaries (76.84\%) having a parent company abroad, i.e. the management of the enterprise was not Slovak, and therefore the corporate culture was foreign. The most frequently monitored financial indicators were the Key Performance Indicators (KPIs) and absolute indicators. Employee turnover, sickness and absenteeism were reported by the enterprises as the most frequently monitored non-financial indicators. Employee fluctuation and stabilisation, as well as the ability to attract talented employees, were regarded by the enterprises as the non-financial indicators that could be influenced by appropriate corporate culture.

Based on the use of statistical methods, we tested the hypotheses established, and both hypotheses were confirmed. Thus, we assert that "less than 40\% of industrial enterprises operating in the Slovak Republic use nonfinancial indicators in addition to financial indicators of company performance" and also claim that "there is dependence between the optimised corporate culture and the achieved performance of industrial enterprises". The foregoing implies that large industrial enterprises certainly need to pay attention to the optimisation (or cultivation) of their corporate culture, which significantly affects the non-financial indicators of company performance. Furthermore, positive results in company performance are a prerequisite for long-term and sustainable company competitiveness.

\section{Conclusion}

This article deals with the impact of corporate culture on the performance of large industrial enterprises in the Slovak Republic, especially on non-financial performance indicators. The research identified individual corporate culture factors, which were divided into three main groups, and also nonfinancial performance indicators. The quantitative research and its subsequent verification by statistical methods showed that both hypotheses initially established were confirmed. It was confirmed that less than $40 \%$ of industrial enterprises operating in the Slovak Republic used non-financial performance indicators and also that there was dependence between the applied corporate culture and the achieved performance of industrial enterprises. In other words, corporate culture has an impact on the performance of industrial enterprises. In the future, it would be beneficial to also attest a group of small and medium-sized enterprises through the same research. In addition, we plan to process the findings from the quantitative research and to propose a set of recommendations for large industrial enterprises. There will be defined individual specific corporate culture factors in proposed set, as well as the procedure of adjusting them such way, that will have an impact on non-financial indicators results and eventually on the overall performance of enterprise.

\section{Acknowledgments}

This contribution was written as part of the implementation of the VEGA 1/0348/17 Project: "The Impact of the Coexistence of Different Generations of Employees on the Sustainable Performance of Organisations".

\section{References and Notes}

[1] Armstrong Competence Consulting \& Competence Research Institute. Výsledky štúdie: Vztah výkonu a firemnej kultúry (Study results: Relationship between performance and corporate culture). ( ) n.d. [2016-6-10]. Available on the Internet: http://www.armstrongcc.sk/fileadmin/user_upload/Publikacie/Na_vykon_zamerana_firemna_kultura.pdf

[2] Ilies, L., Gavrea, C.: The link between organizational culture and corporate performance. (c) 2008. [cit. 2018-15-9]. Available on the Internet: https://www.researchgate.net/publication/46533309

[3] Šihut, Z. 2004. Firemní kultura a lidské zdroje (Corporate culture and human resources). Prague: ASPI. ISBN 80-7357046-7

[4] Klasifikácia podnikov a ich charakteristiky (Classification 
of enterprises and their characteristics). [cit. 2017-02-15].

Available on the Internet: http://www.euroekonom.sk/ekonomia/podnik-a-podnikanie/klasifikacia-podnikov/

[5] Bestvinová V., Vaňová J. 2014. Podnikové hospodárstvo I (Business economy I.). Trnava. AlumniPress. ISBN 978-808096-206-7

[6] Kučerová M., Fidlerová H. 2012. Štatistické metódy (Statistical methods). Trnava: AlumniPress. ISBN 978-80-8096-155-8

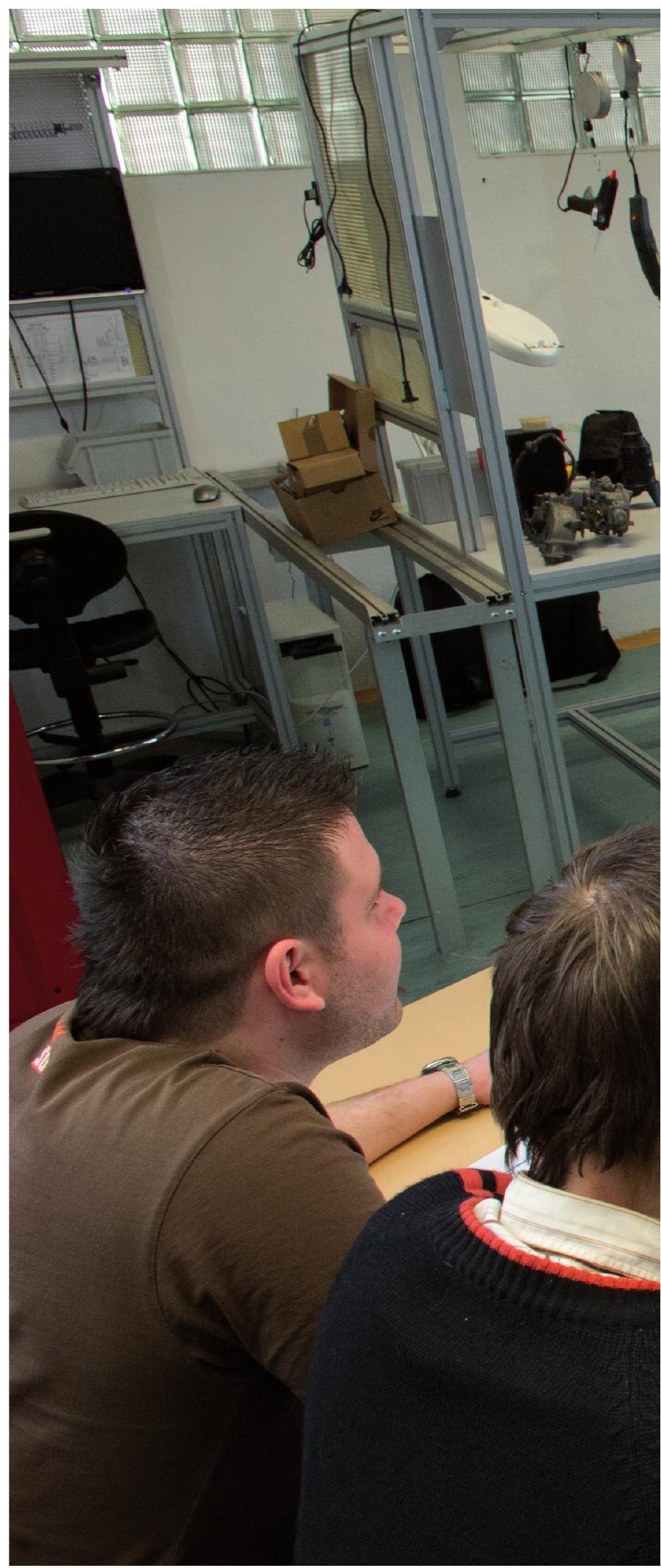

